УДК 330:657.6

$10.17213 / 2075-2067-2021-1-122-132$

\title{
ОСОБЕННОСТИ ПРОВЕДЕНИЯ ПРОЦЕДУРЫ ЭКСПЕРТИЗЫ В СФЕРЕ ЗАКУПОК НЕМАТЕРИАЛЬНЫХ АКТИВОВ
}

\author{
(C) 2021 г. А. В. Лазарев, А. Р. Лазарева, Л. В. Голощапова
}

\section{Российский экономический университет имени Г. В. Плеханова, г. Москва, Россия}

Цель исследования - выполнить обзор теоретической базы процедуры проведения экспертизы в сфере закупки нематериальных активов.

Материалы, методы и условия проведения исследований. Изучены нормативно-правовые акты, а также федеральный закон от 05.04.2013 г. №44-Ф3 «О контрактной системе в сфере закупок товаров, работ, услуг для обеспечения государственных и муниципальных нужд» и федеральный закон от 18.07.2011 г. №223-Ф3 «О закупках товаров, работ, услуг отдельными видами юридических лицฺ».

Задачи исследования - проанализировать и оценить ичелесообразность и эффективность привлечения внешних экспертов к процессу внутреннего контроля в сравнении с использованием труда внутреннего сотрудника в условиях государственных закупок.

Результаты исследования. $B$ статье охарактеризован понятийный аппарат эксперта, рассмотрено понятие закупок нематериальных активов и то, какую часть из них на современном этапе занимает закупка программного обеспечения. Уделено внимание производственной прочедуре закупок программного обеспечения иностранного происхождения, при этом сформирован ответ на вопрос: как выгоднее и эффективнее проводить экспертизу с привлечением сторонних организаций или собственныли силами? Также даны разъяснения по основным ключевым количественным и качественным показателям экспертизы программного обеспечения в условиях санкциионного ограничения и дистантной работы.

Перспектива исследования. $B$ настоящее время актуальна проблема эффекттиного анализа и экспертизы закупок нематериальных активов, потому что они играют значимую роль в формировании имущественного комплекса организаџии. В случае, если закупка сделана некачественно, пострадает учет организаџии и эффективность использования государственных ресурсов.

Ключевые слова: государственные закупки; внешняя экспертиза; внутренняя экспертиза; эксперт; экспертная организация; нематериальные активы; программное обеспечение.

\section{FEATURES OF THE EXPERTISE PROCEDURE IN THE SPHERE OF PROCUREMENT OF INTANGIBLE ASSETS}

\section{(C) 2021 A. V. Lazarev, A. R. Lazareva, L. V. Goloshchapova}

\section{Plekhanov Russian University of Economics, Moscow, Russia}

Purpose of the study is to review the theoretical basis of the examination procedure in the procurement of intangible assets.

Materials, methods and research conditions. The regulatory legal acts, as well as the federal law dated 05.04.2013 №44-FZ «On the contract system in the field of procurement of 
goods, works, services to meet state and municipal needs》 and the federal law dated 18.07.2011 №223-FZ «On procurement of goods, works, services by certain types of legal entities».

The results of the study. The article describes the conceptual apparatus of the expert, considers the concept of purchasing intangible assets and what part of them is currently occupied by the purchase of software. Attention is paid to the production procedure for purchasing software offoreign origin, while the answer to the question is formed: how is it more profitable and efficient to conduct an expert examination - with the involvement of third-party organizations or on their own? Explanations are also given on the main key quantitative and qualitative indicators of software expertise in the conditions of sanctions restrictions and remote work.

Research objectives is to analyze and evaluate the feasibility and effectiveness of attracting external experts to the internal control process in comparison with the use of the labor of an internal employee.

Research perspective. Currently, the problem of effective analysis and examination of purchases of intangible purchases is urgent, because intangible assets play a significant role in the formation of the property complex of an organization. If the purchase is made poorly, then the accounting of the organization will suffer.

Key words: public procurement; external expertise; internal expertise; expert; expert organization; intangible assets; software; key indicators.

Ежегодно в Российской Федерации рассматривается и принимается большое число законопроектов, связанных с выполнением административного и налогового кодексов, финансового законодательства. В современных условиях одной из самых динамично развивающихся отраслей права является право в сфере государственных закупок. Так как это сравнительно молодая отрасль права, в ней часто происходят различные корректировки, необходимые для того, чтобы более детально проработать каждый этап в процессах. Государство ставит одной из ключевых своих задач получение максимальных результатов при осуществлении закупки товаров, работ, услуг в силу влияния на социально-экономические параметры развития государства.

Благодаря появлению единой информационной системы (ЕИС) сбор статистических данных по интересующим заявкам существенно упростился. Анализируя осуществленные закупки, можно сделать вывод, что основная доля приобретения активов приходится на материальные активы - около $90 \%$. Оставшуюся часть занимают нематериальные активы, большая доля которых - ИТ (далее под ИТ используется понятие «программное обеспечение»).
О правилах закупки программного обеспечения говорится в постановлении правительства РФ от 16.11.2015 г. №1236, по которому доступны закупки программного обеспечения (далее ПО) только производства стран ЕАЭС. В этом же постановлении есть правила формирования единого реестра программного обеспечения, список которых выложен на сайте Минсвязи РФ (https:/reestr. minsvyaz.ru/rules/obshchie_dokumenty/).

В реестр вносят программное обеспечение, которое соответствует следующим требованиям:

— право на ПО принадлежит РФ, региону, муниципальному образованию, российскому гражданину, НКО или коммерческому предприятию без преобладающего иностранного участия;

- ПО введено в оборот в России, реализуется также на территории всей России и не имеет ограничений, установленных иностранными государствами, для использования в РФ;

- сумма выплат иностранным юридическим лицам по лицензионным и прочим договорам, которые дают право на использование ПО, составляет менее 30 \% выручки;

- сведения о ПО не содержат государственную тайну; 
- ПО соответствует требованиям безопасности информации;

- у правообладателя есть лицензия;

- ПО принудительно не обновляется и не управляется из-за рубежа;

- гарантийным обслуживанием и техподдержкой занимается гражданин России или организация без преобладающего иностранного участия.

Заказчики, как правило, ошибаются, ссылаясь на закупку у единственного поставщика программного обеспечения. Нельзя забывать, что в соответствии с п. 13 ч. 1 ст. 93 Закона №44-Ф3 закупка возможна лишь в условиях создания произведения литературы и искусства. Для программного обеспечения закупка возможна только в случае, если цена контракта меньше 300 тыс. руб. (или 600 тыс. руб. для заказчиков из п. 5 ч. 1 ст. 93).

Поэтому в данной сфере существует немало актуальных проблем таких, как:

— коррупция;

— эффективное использование ИТ в процедуре государственных закупок;

- подготовка и поиск высококвалифицированных кадров и прочее.

Особенно остро стоит вопрос проведения экспертизы товаров, работ, услуг. Одна из значительных проблем в области экспертизы на текущий день - это проведение экспертизы в сфере государственных закупок нематериальных активов. Именно на этой причине мы решили заострить свое внимание.

Классификация активов на материальные и нематериальные пришла из области бухгалтерского учета.

Согласно ПБУ 2-4 и Налоговому кодексу РФ нематериальный актив - это актив, соответствующий следующим показателям:

— не является вещью;

- способен приносить экономическую выгоду;

- срок использования свыше 12 месяцев, в течение которых организация не планирует продажу актива;

- у организации есть право на данный актив (например, патент или иные документы);

- первоначальная стоимость актива (фактическая его стоимость) может быть определена.

Пример нематериальных активов: произведения литературы, искусства и результаты деятельности науки, ИТ (программы), товарные знаки, деловая репутация.

Перед тем как перейти к рассмотрению вышеуказанной проблемы, необходимо обозначить второй из используемых терминов, а именно термин «экспертиза».

Экспертиза (возник от латинского слова expertus - опытный, сведущий) означает исследование, проводимое лицом, обладающим глубокими познаниями в определенной области - экспертом; это может быть наука, искусство, ремесло, строительство или жизненная мудрость, используемая для решения возникших споров. Как правило, экспертиза проводится по поручению заинтересованного лица.

Полагаясь на законодательную базу, а именно - федеральный закон от 05.04.2013 г. №44-Ф3 (ред. от 27.12.2019 г.), делаем вывод, что заказчик должен провести экспертизу при приемке товара либо результатов выполнения работ, оказания услуг. Приемка товаров и услуг по федеральному закону от 05.04.2013 г. №44-Ф3 (ред. от 27.12.2019 г.) - этап достаточно важный, так как от грамотно проведенной приемки во многом зависит возможность защиты интересов заказчика в том случае, если предоставленный поставщиком товар или оказанная услуга не соответствуют условиям контракта.

Согласно статье 94 Федерального закона от 05.04.2013 г. №44-Ф3 (ред. от 27.12.2019 г.) экспертиза в закупках может носить обязательный и необязательный характер. В результате заказчик обязан проводить экспертизу для проверки результатов, предусмотренных контрактом, в части их соответствия условиям контракта.

Он может произвести экспертизу одним из двух способов:

- своими силами;

- с привлечением сторонних экспертных организаций или экспертов.

При этом если заказчик решает проводить экспертизу своими силами, он может создать приемочную комиссию, состоящую не менее чем из пяти человек. Независимо от выбранного способа проведения экспертизы итоги экспертизы должны быть оформлены мотивированным заключением эксперта.

Для многих компаний-заказчиков возникает ряд вопросов выбора: 
— кто же будет выполнять данную работу;

— будет ли это внутренняя служба или сторонняя организация;

- какими критериями пользоваться при принятии решения в ту или иную пользу (табл. 1).

Очевидно, что при сравнении двух подходов к принятию решений важную роль играет стоимостный критерий.

Оцениваются:

- совокупные затраты, которые понесет компания, выполняя экспертизу своими силами;

- стоимость контракта со сторонней организацией на проведение экспертизы.

Если в итоге первый показатель меныше второго, то это означает, что организации выгоднее производить экспертизу своими силами, то же верно и в обратную сторону: если первый показатель больше второго выгоднее заключить контракт с экспертной компанией. Но стоит акцентировать внимание на том, что данное правило действительно, если нет других факторов, резко влияющих на принятие решения. К таким факторам можно отнести ведомственные интересы компании, стратегические интересы, заинтересованность менеджмента и др.

Если говорить о случаях, в которых проведение экспертизы необязательно, то решение принимается точно таким же образом, только добавляется критерий полученной выгоды (выгода, если экспертизу провели или ее вообще не проводили).

В федеральном законе от 05.04.2013 г. №44-Ф3 (ред. от 27.12.2019 г.) указано, что заказчик обязан привлечь экспертов, если закупка осуществляется у единственного поставщика.

По нашему мнению, вышеизложенная методика по принятию решения достаточно эффективна и может быть использована на практике. Наверное, для конкретной компании следует ввести весовые значения для критериев оценки, но стандартной методологией заложить значимость критериев не представляется возможным. Стоит отдельно отметить, что нельзя передавать экспертизу на аутсорсинг - это процессы, связанные с ключевыми компетенциями компании.

Таблица 1

Критерии, влияющие на принятие решения в системе государственных закупок (составлено авторами)

\begin{tabular}{|c|c|c|}
\hline Критерий & Своими силами & Сторонняя организация \\
\hline $\begin{array}{l}\text { Наличие } \\
\text { компетентных } \\
\text { кадров }\end{array}$ & $\begin{array}{l}\text { При наличии квалифицирован- } \\
\text { ных кадров организации целе- } \\
\text { сообразно проводить эксперти- } \\
\text { зу своими силами }\end{array}$ & $\begin{array}{l}\text { При недостатке кадров или при не- } \\
\text { достатке квалификации кадров (не- } \\
\text { достаток документов/сертификатов, } \\
\text { подтверждающих компетентность) } \\
\text { целесообразно передать экспертизу } \\
\text { в стороннюю организацию }\end{array}$ \\
\hline $\begin{array}{l}\text { Наличие опыта } \\
\text { приема исполнения } \\
\text { контрактов }\end{array}$ & $\begin{array}{l}\text { Если у организации есть опыт ка- } \\
\text { саемо конкретного объекта конт- } \\
\text { ракта, то целесообразно прово- } \\
\text { дить экспертизу своими силами }\end{array}$ & $\begin{array}{l}\text { Если у организации нет опыта каса- } \\
\text { емо конкретного объекта контракта, } \\
\text { то целесообразно привлечь сторон- } \\
\text { нюю организацию }\end{array}$ \\
\hline $\begin{array}{l}\text { Наличие матери- } \\
\text { ально-технического } \\
\text { обеспечения (специ- } \\
\text { альные лаборатории, } \\
\text { исследовательские } \\
\text { центры и прочее) }\end{array}$ & $\begin{array}{l}\text { При наличии обеспечения це- } \\
\text { лесообразно производить экс- } \\
\text { пертизу своими силами }\end{array}$ & $\begin{array}{l}\text { При отсутствии необходимого обес- } \\
\text { печения целесообразно передать в } \\
\text { стороннюю организацию }\end{array}$ \\
\hline $\begin{array}{l}\text { Ведомственные } \\
\text { интересы }\end{array}$ & $\begin{array}{l}\text { При наличии интересов целе- } \\
\text { сообразно передать в сторон- } \\
\text { нюю организацию }\end{array}$ & $\begin{array}{l}\text { При наличии противоречий целесо- } \\
\text { образно передать в стороннюю орга- } \\
\text { низацию }\end{array}$ \\
\hline
\end{tabular}


Например, если компания готовит хлебобулочные изделия, передавать на аутсорсинг экспертизу муки нецелесообразно.

Говоря о процессе закупки информационного обеспечения для компании, стоит упомянуть о том, что широко распространена экспертиза сторонних организаций, так как при закупке сложного нестандартного программного обеспечения возникает необходимость качественной проверки и тестирования работоспособности, в том числе и проведения нагрузочного тестирования. Сейчас идет повсеместная глобализация и компьютеризация многих процессов. Для выполнения основных задач на персональном компьютере должно быть установлено определенное программное обеспечение, но не все компании могут найти техническую составляющую, которая полностью удовлетворяет потребность в проводимых бизнес-операциях. Из-за этого многие компании заказывают проведение работ по первичному анализу и производству уникальных программ под свои нужды. В этом случае очень маловероятно наличие необходимых ресурсов на осуществление качественной внутренней экспертизы. Иными словами, для заказчика увеличивается вероятность получить нерабочий продукт или недостаточно эффективный по сравнению с аналогичным.

Помимо принятия решения об экспертизе можно выделить проблему, связанную со сложностью в постановке ключевых показателей эффективности на этапе составления технического задания. Другими словами, если при выставлении технического задания не все этапы, показатели будут продуманы и обозначены, поставщик может выдать сырой продукт, ссылаясь на заключенный договор.

Для того чтобы эффективно бороться с этим, следует привлекать экспертов уже на этапе составления технического задания.

В качестве экспертов не могут выступать:

- физические лица, являющиеся должностным лицом заказчика, подрядчика не менее чем 2 года назад;

- физические лица, имеющие имущественные интересы;

- физические лица, обладающие родственными связями с лицами, работающими у заказчика, поставщика;
- юридические лица, в которых заказчик или поставщик имеет более чем $20 \%$ голосов или доли в уставном капитале;

- юридические или физические лица в случае, если на них может оказывать прямое или косвенное влияние заказчик или поставщик.

Для решения данного вопроса помимо привлечения экспертов на этапе составления технического задания (далее Т3) широко применяется процедура двухэтапного конкурса. Двухэтапный конкурс позволяет собрать необходимую информацию о предмете закупки от участников рынка еще до заключения контракта и использовать полученную информацию для более качественного составления ТЗ. У данного типа конкурса есть одна важная особенность - заказчик имеет право изменять ТЗ и критерии оценки. В процессе реализации могут возникнуть дополнительные требования, которые должны быть реализованы, если они входят в ранее оговоренные рамки.

Во многих сферах в качестве оценки эффективности работы программного обеспечения можно использовать такой показатель, как цена транзакции. Цена транзакции показывает затраченный денежный ресурс на проведение одной операции (например, операции формирования банковской выписки или формирования потребности в закупке). Также можно использовать и временной показатель, например, время, потраченное на осуществление необходимой операции. Помимо стоимостной или количественной оценки эффективности работоспособности ПО можно использовать и качественный показатель, например, удобство и простота при работе с программой.

Широкое распространение получил метод под названием IT Scorecsrd, суть которого заключается в следующем: выбираются четыре сбалансированных направления влияния ПО на бизнес-компании. Как правило, выделяют следующие направления:

- помощь в развитии бизнеса компании;

- повышение качества продукции (для внутренних и внешних пользователей);

- повышение производительности труда;

- повышение качества и уменьшение сроков принятия решений.

Данные показатели, по нашему мнению, можно привести для примера с целью обоз- 
начения сферы применения, исходя из отрасли компании заказчика (табл. 2).

Также часто можно встретить такие показатели, как:

- доля затрат на информационные технологии в компании;

- количественный показатель, показывающий, сколько ИТ приходится на одного сотрудника (количественное и ценовое выражение в разрезе всей компании и по отделам);

- доля электронных операций;

- доля затрат на НИОКР в себестоимости продукта.

Данные показатели применяются во время экспертизы при исполнении контракта, и в случае некорректной работы необходимо выдвинуть замечания по доработке поставщику.

Возможны ситуации, где объект, по которому проходит экспертиза, очень сложен, и осуществление данного процесса своими силами невозможно, а привлечение сторонних организаций может стоить не меньше, чем сам объект закупки. В данных ситуациях экспертиза проводится поверхностно с произвольным углублением в некоторых нюансах. Данные методы очень часто используются при экспертизе нематериальных активов.

Пример: экспертиза по исполнению контракта на ИТ-внедрение определенного программного обеспечения. Проверить работоспособность программы - это одно, а совсем другое - открыть сам код и провести его детальный анализ. Также стоит отметить сложность в экспертизе по ИТ-продуктам, а именно шифрование информации и контроль работоспособности с основными контрагентами и соблюдение требований. Данной экспертизе в последнее время уделяют все

Таблица 2

\section{Сравнение показателей при оценке экспертной группой ПО (составлено авторами)}

\begin{tabular}{|c|c|c|c|}
\hline \multirow{2}{*}{ Показатель } & \multirow{2}{*}{ Комментарии } & \multicolumn{2}{|c|}{$\begin{array}{c}\text { Сфера деятельности компании } \\
\text { заказчика и степень применения }\end{array}$} \\
\hline & & $\begin{array}{c}\text { Компании } \\
\text { гос. сектора }\end{array}$ & $\begin{array}{l}\text { Частные } \\
\text { компании }\end{array}$ \\
\hline Цена транзакции & $\begin{array}{l}\text { Традиционно данный показатель } \\
\text { считается наиболее часто исполь- } \\
\text { зуемым }\end{array}$ & Важен & Важен \\
\hline Срок окупаемости & $\begin{array}{l}\text { Используется в том числе для срав- } \\
\text { нения разных ПО }\end{array}$ & Средняя & Важен \\
\hline Доходность & $\begin{array}{l}\text { Используется частными компания- } \\
\text { ми, если речь не идет о закупках чего- } \\
\text { либо с целью дальнейшего экспорта }\end{array}$ & Нет & Важен \\
\hline $\begin{array}{l}\text { Снижение задержек } \\
\text { при поставках }\end{array}$ & $\begin{array}{l}\text { Издержки сокращаются как по } \\
\text { времени, так и по используемым } \\
\text { ресурсам }\end{array}$ & Важен & Важен \\
\hline $\begin{array}{l}\text { Уменьшение несни- } \\
\text { жаемых остатков }\end{array}$ & $\begin{array}{l}\text { Данный показатель актуален не } \\
\text { для всех отраслей гос. закупок }\end{array}$ & Средняя & Важен \\
\hline $\begin{array}{l}\text { Повышение обора- } \\
\text { чиваемости запасов }\end{array}$ & $\begin{array}{l}\text { Данный показатель актуален не } \\
\text { для всех отраслей гос. закупок }\end{array}$ & Средняя & Важен \\
\hline $\begin{array}{l}\text { Сокращение доли } \\
\text { незавершенной про- } \\
\text { дукции }\end{array}$ & $\begin{array}{l}\text { Данный показатель актуален не } \\
\text { для всех отраслей гос. закупок }\end{array}$ & Средняя & Важен \\
\hline $\begin{array}{l}\text { Повышение произ- } \\
\text { водительности ра- } \\
\text { ботников }\end{array}$ & $\begin{array}{l}\text { Один из важнейших показателей } \\
\text { для многих компаний }\end{array}$ & Важен & Важен \\
\hline
\end{tabular}


большее и большее внимание, это связано с риском утечки данных.

Рассмотрим вышеуказанные положения на практическом примере (табл. 3).

По мнению многих экспертов в экономике, в настоящее время в РФ сформирована достаточно прозрачная система закупок товаров. По нашему же мнению, данное утверждение верно лишь отчасти, поскольку если говорить о появлении механизма, предоставляющего возможность централизо- ванного размещения в единой информационной системе всей информации о закупках, a также агрегацию поставщиков и данных о них, то действительно прозрачная система закупок сформирована, если же более широко применять данное понятие прозрачности, то не все его пункты выполнены на сегодняшний день, но ведется дальнейшая работа по совершенствованию.

Например, по данным Министерства финансов РФ, за 1-3 квартал 2018 г. при про-

Таблица 3

Типовой пример выбора условия проведения экспертизы в АО

\begin{tabular}{|c|c|}
\hline \multicolumn{1}{|c|}{ Условие } & \multicolumn{1}{|c|}{ Вопрос } \\
\hline $\begin{array}{l}\text { Организации «Вымпел союз» необходимо } \\
\text { произвести экспертизу при приобретение про- } \\
\text { граммного обеспечения }\end{array}$ & $\begin{array}{l}\text { Произвести экспертизу своими силами или } \\
\text { с помощью сторонней организации? }\end{array}$ \\
\hline \multicolumn{2}{|c|}{ Этапы для принятия решения } \\
\hline
\end{tabular}

Первый вопрос, который ставит перед собой компания: каким способом будет происходить экспертиза - внутренними силами или с привлечением экспертной организации? Необходимые действия, с которых компании стоит начать - это сбор необходимой информации для принятия решения. В «Вымпел союз» есть внутреннее подразделение, выполняющее экспертизу ИТ-продуктов, но весь отдел задействован на другую активность в компании.

Если компания будет нанимать нового сотрудника на постоянной или срочной основе, ей необходимо будет произвести следующие затраты:

1) заработная плата сотрудника и прочие сборы на персонал составят 77460 руб.;

2) приобретение дополнительного ноутбука обойдется в 47000 руб.;

3) увеличение других офисных затрат не планируется, так как в офисе «Вымпел союз» уже есть рабочее место со всем необходимым.

Итого совокупные затраты сроком на полгода на нового сотрудника составят:

$77460 \times 6+47000=511760$ руб.

Предположим, свои услуги предложат две организации: «Бизнес-экспертиза» и «ПроЭкспертиза».

«Бизнес-экспертиза» предлагает выполнить необходимый фронт работ за 1480000 руб. выполнить за 1150000 руб.

\section{Решение}

«Вымпел союз» стоит заключить контракт с «Про-Экспертиза»

Пояснения: несмотря на то, что на сумма, затраченная на привлечение нового сотрудника (511760 руб.), существенно меньше суммы контракта с «Бизнес-Экспертиза» (1480000 руб.), разница составляет почти 2,9 раза.

Данное решение принято из-за того, что продукт оценки сложен и нет четкой уверенности, что один привлеченный сотрудник справится с таким объемом, к тому же внутренний отдел экспертизы дал рекомендации обратиться к подрядной организации, так как, по их мнению, для данного проекта сроки слишком короткие. 


\section{Доля выявленных нарушений за период 1-3 квартал 2018 года}

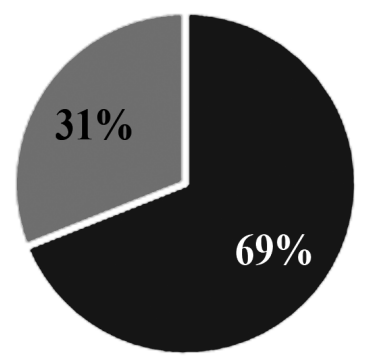

\section{- Проверено процедур Выявлено нарушений}

Рис. 1. Статистика нарушений в процедурах проверок за 2018 г.

ведении плановых и внеплановых проверок в отношении закупок, осуществляемых в соответствии с требованиями Закона о контрактной системе, проверено 18532 процедур определения поставщика (подрядчика, исполнителя), из которых в 5784 процедурах выявлены нарушения (рис. 1).

Подводя итоги, хотелось бы выделить, что у экспертизы в части нематериальных активов есть свои характерные черты и особенности. По мнению авторов статьи, помимо количественных показателей также необходимо применять качественные показатели, хотя на текущий момент зачастую ими пренебрегают. Также нельзя забывать об изменении законодательства. До тех пор, пока в рамках предусмотренного стандарта, продиктованного нам Ф3, есть спорные нюансы и нерегламентированные ситуации, экспертиза будет проходить не на самом высоком уровне.

\section{Литература}

1. Байсаева М.У., Ахмедов С.А., Дагаева Х.Б., Газгериев Ш.Ш. Государственные и муниципальные закупки / Международный журнал прикладных наук и технологий «Integral». — 2019.

2. Белякова Е.В., Рыжая А.А. Управление закупками машиностроительного предприятия / Решетневские чтения. - 2018.

3. Белов B. E. Об изменении гражданского законодательства в условиях формирования контрактной системы в сфере закупок товаров, работ, услуг для обеспечения государственных и муниципальных нужд [Электронный ресурс] // Актуальные проблемы российского права, 2014. — №10. - Режим доступа: http://www.consultant.ru/ (Дата обращения: 20.05.2017).

4. Гусев А. В. Государственные закупки программного обеспечения и услуг по информатизации здравоохранения в 2013-2017 г. / Врач и информационные технологии.

5. Дарищева А. Ф. Закупки, которые целесообразно включать в положение, при закупках у единственного поставщика / Colloquium-journal. - 2019.

6. Зюзгина К.А., Паулов П.А. Государственные закупки: современные проблемы / Бюллетень науки и практики. - 2018.

7. Кичик К.В. Законодательство России о публичных закупках (обзорная статья) [Электронный ресурс] // Публичные закупки: проблемы правоприменения. Материалы Третьей Всероссийской научно-практической конференции (9 июня 2015 г., МГУ им. М.В. Ломоносова). - 2015. - С. 44-56. - Режим доступа: http://www.consultant.ru/ (Дата обращения: 20.05.2017).

8. Косарев K. Что ждет систему госзакупок? [Электронный ресурс] // ЭЖ-Юрист, 2013. — №29. — Режим доступа: http://www. consultant.ru/ (Дата обращения: 20.05.2017).

9. Матевосян С. С. Эффективность закупок для государственных и муниципальных нужд. Правовое регулирование и порядок реализации [Электронный ресурс]. — Режим 
доступа: http://www.consultant.ru/ (Дата обращения: 20.05.2017).

10. Морозов А. А. Эволюция развития механизма правового регулирования договора поставки для государственных нужд в Российской Федерации // Ленинградский юридический журнал. - 2016. — №3 (45). C.99-107.

11. Рубияов В.Н. Мониторинг государственных закупок как механизм противодействия коррупции // Евразийская адвокатура. 2017. - №1. - C. 143-145.

12. Ткаченко А.И. Сценарии изменения политики государства в сфере импортозамещения корпоративного софта / Научный журнал. - 2018.

13. Положение по бухгалтерскому учету «Учет нематериальных активов» (ПБУ 14/2007) (с изм. и доп.).

14. Федеральный закон от 05.04.2013 г. №44-Ф3 (ред. от 28.12.2016 г.) «О контрактной системе в сфере закупок товаров, работ, услуг для обеспечения государственных и муниципальных нужд» (с изм. и доп., вступ. в силу с 09.01.2017 г.).

15. Федеральный закон «О закупках товаров, работ, услуг отдельными видами юридических лиц» от 18.07.2011 г. №223-Ф3 (последняя редакция).

\section{References}

1. Bajsaeva M.U., Ahmedov S.A., Dagaeva H.B., Gazgeriev Sh. Sh. Gosudarstvennye i municipal'nye zakupki [State and municipal procurement] / Mezhdunarodnyj zhurnal prikladnyh nauk i tehnologij «Integral» [International Journal of Applied Sciences and Technologies «Integral»]. - 2019.

2. Beljakova E.V., Ryzhaja A.A. Upravlenie zakupkami mashinostroitel'nogo predprijatija [Management of procurement of machinebuilding enterprises] / Reshetnevskie chtenija [Reshetnev readings]. - 2018.

3. Belov V.E. Ob izmenenii grazhdanskogo zakonodatel'stva $\mathrm{v}$ uslovijah formirovanija kontraktnoj sistemy v sfere zakupok tovarov, rabot, uslug dlja obespechenija gosudarstvennyh i municipal'nyh nuzhd [About changes in civil legislation in the conditions of formation of the contract system in procurement of goods, works, services for ensuring the state and municipal needs] [Jelektronnyj resurs] // Aktual'nye problemy rossijskogo prava, 2014 [Actual problems of Russian law, 2014]. — №10. — URL: http:// www.consultant.ru/ (Date accessed: 20.05.2017).

4. Gusev A.V. Gosudarstvennye zakupki programmnogo obespechenija $i$ uslug po informatizacii zdravoohranenija v 2013-2017 g. [Public procurement of software and services for healthcare Informatics in 2013-2017] / Vrach i informacionnye tehnologii [Doctor and information technology].

5. Darishheva A.F. Zakupki, kotorye celesoobrazno vkljuchat' v polozhenie, pri zakupkah $\mathrm{u}$ edinstvennogo postavshhika [Procurement, which is advisable to include in the regulation, when purchasing from a single supplier] / Colloquium-journal. - 2019.

6. Zjuzgina K.A., Paulov P.A. Gosudarstvennye zakupki: sovremennye problemy [State procurement: modern problems] / Bjulleten' nauki i praktiki [Bulletin of Science and practice]. - 2018.

7. Kichik K. V. Zakonodatel'stvo Rossii o publichnyh zakupkah (obzornaja stat'ja) [Legislation of Russia on public procurement (review article)] [Jelektronnyj resurs] // Publichnye zakupki: problemy pravoprimenenija. Materialy Tret'ej Vserossijskoj nauchno-prakticheskoj konferencii (9 ijunja 2015 g., MGU im. M.V. Lomonosova) [Public procurement: problems of law enforcement. Materials of the Third All-Russian Scientific and Practical Conference (June 9, 2015, Lomonosov Moscow State University)]. — 2015. - Pp. 44 56. — URL: http://www.consultant.ru/ (Date accessed: 20.05.2017).

8. Kosarev K. Chto zhdet sistemu goszakupok? [What awaits the public procurement system?] [Jelektronnyj resurs] // JeZh-Jurist, 2013. - №29. — URL: http://www.consultant. ru/ (Date accessed: 20.05.2017).

9. Matevosjan S.S. Jeffektivnost' zakupok dlja gosudarstvennyh i municipal'nyh nuzhd. Pravovoe regulirovanie i porjadok realizacii [Efficiency of procurement for state and municipal needs. Legal regulation and implementation procedure] [Jelektronnyj resurs]. - URL: http:// www.consultant.ru/ (Date accessed: 20.05.2017).

10. Morozov A. A. Jevoljucija razvitija mehanizma pravovogo regulirovanija dogovora postavki dlja gosudarstvennyh nuzhd $\mathrm{v}$ Rossijskoj Federacii [Evolution of the mechanism of legal regulation of the contract of supply for 
public use in the Russian Federation] // Leningradskij juridicheskij zhurnal [Leningrad law journal]. — 2016. — №3 (45). — Pp. 99-107.

11. Rubcov V.N. Monitoring gosudarstvennyh zakupok kak mehanizm protivodejstvija korrupcii [Monitoring of public procurement as a mechanism of counteraction of corruption]// Evrazijskaja advokatura [Eurasian advocacy]. — 2017. — №1. - Pp. 143-145.

12. Tkachenko A.I. Scenarii izmenenija politiki gosudarstva $\mathrm{v}$ sfere importozameshhenija korporativnogo softa [Change scenarios of the state policy in the sphere of import substitution corporate software] / Nauchnyj zhurnal [Scientific journal]. - 2018 .

13. Polozhenie po buhgalterskomu uchetu «Uchet nematerial'nyh aktivov»[The regula- tion on accounting «Accounting of intangible assets»] (PBU 14/2007) (s izm. i dop.).

14. Federal'nyj zakon ot 05.04.2013 g. №44FZ (red. ot 28.12.2016 g.) «O kontraktnoj sisteme v sfere zakupok tovarov, rabot, uslug dlja obespechenija gosudarstvennyh i municipal'nyh nuzhd» [Federal law of 05.04.2013 №44-FZ (ed. by 28.12 .2016$)$ «On the contract system in procurement of goods, works, services for state and municipal needs»)] (s izm. i dop., vstup. v silu s 09.01.2017 g.).

15. Federal'nyj zakon «O zakupkah tovarov, rabot, uslug otdel'nymi vidami juridicheskih lic» ot 18.07.2011 g. №223-FZ (poslednjaja redakcija) [Federal Law «On Procurement of Goods, Works, and Services by Certain Types of Legal Entities»» of 18.07.2011 №223-FZ (latest version)].

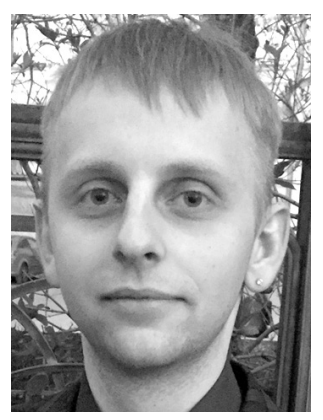

Лазарев Артур Викторович - студент 2-го курса магистратуры факультета экономики торговли и товароведения Российского экономического университета им. Г. В. Плеханова.

Lazarev Artur Viktorovich - 2nd year master's student of the Faculty of Economics of Trade and Commodity Science, Plekhanov Russian University of Economics.

117997, г. Москва, Стремянный пер., 36

36 Stremyanny ln., 117997, Moscow, Russia

E-mail: 789art123@gmail.com 

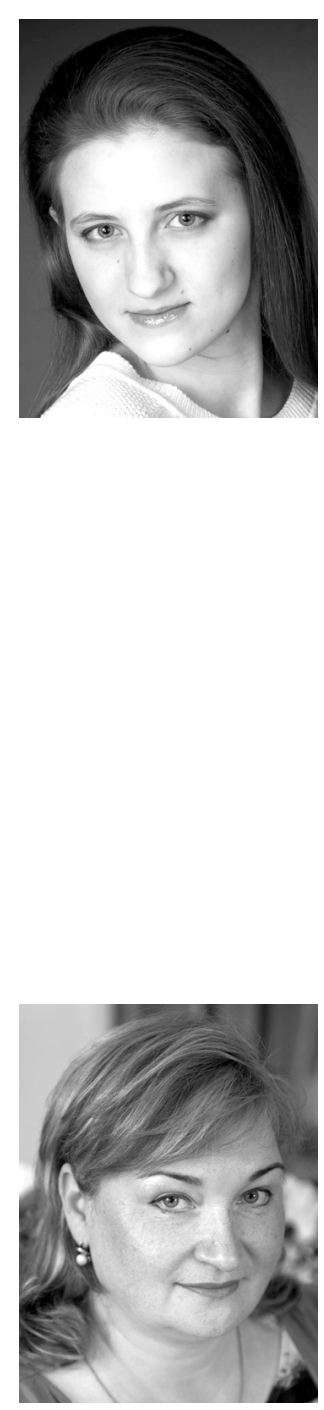

Лазарева Анастасия Романовна - студентка 2-го курса магистратуры факультета экономики торговли и товароведения Российского экономического университета им. Г.В. Плеханова.

Lazareva Anastasia Romanovna - 2nd year master's student of the Faculty of Economics of Trade and Commodity Science, Plekhanov Russian University of Economics.

117997, г. Москва, Стремянный пер., 36

36 Stremyanny ln., 117997, Moscow, Russia

E-mail: anstasialazareva1996@mail.ru

Голощапова Людмила Вячеславовна - кандидат экономических наук, доцент базовой кафедры финансового контроля, анализа и аудита Главного контрольного управления города Москвы Российского экономического университета имени Г.В. Плеханова.

Goloshchapova Liudmila Vyacheslavovna - Candidate of Economic Sciences, Associate Professor of the Basic Department of Financial control, Analysis and Audit of the Main Control Department of Moscow, Plekhanov Russian University of Economics.

117997, г. Москва, Стремянный пер., 36

36 Stremyanny ln., 117997, Moscow, Russia

E-mail: cool.lvg2012@yandex.ru 